\title{
A Comparative Study on the Integration of Turkish Students into Society: A Case Study of Algerian and Ghanaian Students in Ankara, Turkey
}

\author{
Akilu Murtala \\ Migration Policies and Research, Department of Sociology, Faculty of Social Sciences, Ankara Yildirim Beyazit University, Turkey
}

\begin{abstract}
This research was aimed at comparing the Algerian and Ghanaianinternational students to ascertain which of the two categories of students integrates into the Turkish society easier. The elements of integration considered in this study were Turkish language acquisition and socialization.To ascertain which of the two groups is faster in learning the Turkish language, interviews were held with some Turkish language teachersandquestionnaires were administered to the international students from the two countries. Another questionnaire was administered to the students to establish their level of socialization. Separate focus group discussions were also held with the two groups of students. The data was analysed using the approach of content analysis. The results indicated an overall higher performance of the Algerian students in terms of Turkish language acquisition, albeit with some limitation in writing skills, but also a higher level of socialization of the Ghanaian students compared to the Algerian students.
\end{abstract}

Keywords: integration, socialization, international students

\section{Introduction}

Migration has been with the human population since time immemorial. For various reasons, human beings even from the depth of history were known to be moving from one place to another, one town to another and indeed from one country to another, either individually or in groups.The Republic of Turkey has been reported to be a country of emigration in most literature. Because of its strategic location, it has also been severally referred to as a country of transit, used by other nationals especially from Sub-Saharan African countries before continuing their journey to Europe.However, the country is fast becoming a preferred destination for many migrants. But this changing trend is not very recent. Between 1934 to 1945 , 229,870 refugees and other immigrants were reported to have migrated to Turkey. The trend has since continued up to present day, with number of migrants in the country seeing appreciation from year to year. For example, the Turkish Statistical Institute (TURKSTAT) reported that in 2017, Turkey experienced a 22.4 percent increase in the number of people coming into the country ${ }^{1}$. In 2018, there was a further appreciation of this rate to $23.8 \%^{2}$. Whereas vast majority of the immigrants are refugees from Syria, there are many other foreign nationals living in Turkey for varied reasons. One of such reasons is education. Not every migrant leaves his/her country of origin for economic reason or because of any ensuing turbulence. Others travel abroad to seek higher education. In 2007, there were said to bemore than 3 million students studying outside their home country ${ }^{3}$.Ten years

\footnotetext{
${ }^{1}$ Immigration to Turkey up 22.4 percent in 2017, TurkStat says | Daily Sabah

${ }^{2}$ Immigration to Turkey up by $23.8 \%$ in 2018 : TurkStat (aa.com.tr) ${ }^{3}$ Rienties, B., Beausaert, S., Grohnert, T. et al Understanding academic performance of international students: the role of ethnicity, academic and social integration. High Educ 63, 685-700 (2012). https://doi.org/10.1007/s10734-011-9468-1
}

later (2017), UNESCO reported that in excess of 5 million students across the globe pursued their bachelors and post graduate studies outside their countries of origin ${ }^{4}$. According to an OECD report, the number of undergraduate and postgraduate students studying in a foreign country will reach 8 million by 2025 . Obviously, there is the realization that higher education represents a critical factor in innovation and human capital development, and it plays a central role in the success and sustainability of the knowledge economy (Dill and Van Vught, 2010). This explains the motivation of students to seek quality education even if it must be outside their home countries.

Just like many other higher institutions of learning in different countries across the globe, institutions in Turkey have also opened their doors to international students for purposes of diversification, which is a crucial component of global education. On the other hand, students around the world have been favourably responding to the opportunities the country presents them because of the high quality of education, low tuition fees, low cost of living among others. Hitherto, movement of students was predominantly from east to west. But the trend is gradually changing in recent years, with students opting to study in countries including Malaysia, China, Japan, New Zealand, South Korea, Australia and of course Turkey and many others ${ }^{6}$. In the year 2019, the number of international students in Turkey stood at $185,047^{7}$.

\footnotetext{
${ }^{4}$ United Nations Educational, Scientific and Cultural Organization, UNESCO. (2009). Global edu-cation digest. Paris: UNESCO Institute for Statistics

${ }^{5}$ Dill, D. D., \& van Vught, F. A. (2010). National Innovation and the Academic Research Enterprise: Public Policy in Global Perspective. Johns Hopkins University Press.

${ }^{6}$ The International mobility of students in Asia and the Pacific; 2013 (unesco.org)

${ }^{7}$ https://www.studyinturkey.gov.tr/StudyinTurkey/_PartStatistic
} 
Whatever reason is attributed to the mobility of migrants, given that individuals within the same country can have different ways of life depending on which part of the country they are found,such differences are likely to be more profound when movements involve crossing borders. This necessitates the concept of integration which explains the mutual adaptation between these migrants and the receiving or destination countries. Integration has been defined by the International Organization of Migration (IOM) as the process by which migrants become accepted into society, both as individuals and as groups. It refers to a two way process of adaptation by migrants and host societies and it implies consideration of the rights and obligations of migrants and host societies, of access to different kinds of services and the labour market, and of identification and respect for a core set of values that binds migrants and host communities in a common purpose (IOM, 2011) $)^{8}$. The process of migrant integration entails the processes in their ability to socialize, find jobs, access health facilities and coexist with the indigenes in a harmonious manner. The ability of migrants to do all these is contingent on both the immigrants and the indigenes as well as governmental policies.

Undoubtedly, the success of integration is essential for not just the gains from migration, but also for the well-being of migrants, security, social harmony and the general prosperity of the society. However, a common assumption in higher education is that academic integration which refers to the extent to which students adapt to the academic way-oflife (Tinto 1975), of international students is not wellaligned with the requirements of higher educational institutes (Asmar 2005; Barrie 2007; Jochems et al 1996; Morrison et al 2005; Russell et al 2010 cited in Rientieset al $(2012)^{9}$.

\subsection{Problem statemen}

Although there are programstaught in English in some schools in Turkey, majority of the programs are offered in Turkish language which is the official language of the country. For international students whose programmes are in Turkish, learning the Turkish language is not just for interpersonal interaction with the indigens, but also an important determinant of their success in their fields of study. Students whose programs are in Turkish but are unable to acquire the language up to the required $\mathrm{C} 1$ level have to disappointedly return to their countries with unaccomplished mission. It suffices to say that, in Turkey just like any other places in the world, without proper integration, one's educational journey is in danger, and can even get truncated.

Aside the educational purpose, in Turkey, although there Kurds who also speak Kurdish language, they are in the minority. About $85-90 \%$ of the population in Turkey speak Turkish as their mother tongue. Being the official language

\footnotetext{
${ }^{8}$ IOM and Migrant Integration

${ }^{9}$ Rienties, B., Beausaert, S., Grohnert, T. et al Understanding academic performance of international students: the role of ethnicity, academic and social integration. High Educ 63, 685-700 (2012). https://doi.org/10.1007/s10734-011-9468-1
}

of the country, it is also used in public institutions, in schools, by the media and by overwhelming majority Turkish citizens in their day-to-day life for both speech and writing. Students' ability to integrate and enjoy their lives while in the country hugely hinges on their ability to learn the Turkish language, otherwise, life becomes difficult for them.

\subsection{Objectives of the study}

More generally, the aim of this research was to compare international students from two different countries to ascertain if one of them integrates into the Turkish community better than the other. Thus, the study aims to establishwhich of the two groups of students learn the Turkish language faster, and which of the two socializes more.

\section{Literature Review}

This chapter looked at the literature review. This included the theoretical framework underlying this study as well as some related studies in the area under study.

\subsection{Theoretical framework}

The issue of integration has engaged the attention of many scholars who had strived and keep striving to throw more light on the phenomenon in order to engender adequate understanding of the subject matter. To this end, several theories have been propounded to explain integration processes. These theories are not only diverse, but also contradictory to some extent. Some of these are explained below:

\subsubsection{Assimilation theory}

Although the word assimilation does not have a generally accepted definition, it can be explained as the attenuation of distinction based on ethnic origin. Proponents of this paradigm argue that for successful integration of migrants into host communities, migrants need to do away with their old ways of doing things which they had acquired while in their countries of origin, and then adopt the culture of their host societies as a new way of life. Warner and Srole (1945) explained that where this mechanism of integration is used, over time, migrants behaviour will increasingly become similar to that of natives and they termed this process of change as "straight line assimilation"10. This concept has since been accepted in sociological literature. The theory of assimilation finds traction with the popular adage "when in Rome, do as the Romans do". This approach may be good for migrants who are permanently relocating to the destination countries, but the same cannot be said about international students who are only spending a few years in their host country, and will return to their respective countries upon completion of their studies. Even in cases where students opt to stay in the host countries in which they obtained higher education to work, they mostly visit their home countries from time to time during vacations. The question then is, how are they going to be able to relate with

${ }^{10}$ Warner W.L., Srole L., 1945, The Social Systems of American Ethnic Groups, New Haven, YaleUniversity Press. 
their relatives and members of their communities upon their return if they must forget every rule that guides their interaction? This contention among others is what has led to a radical blow on the assimilation theory, necessitating the proposal of another theory that addresses this concern.

\subsubsection{Multicultural theory}

Multiculturalism is an approach that seeks to address the problem with the assimilation theory. Multiculturalism has been defined by Ivison as a broad array of theories, attitudes, beliefs, norms, practices and policies that seek to provide public recognition of and support for accommodation of non-dominant cultural groups (Ivison, 2011) ${ }^{11}$. Thus, with this theory, the proponents are of the view that different cultures of immigrants should be integrated into society so that migrants do not have to abandon their own culture just because they have found themselves in a new environment. Rather than unlearning their culture, they maintain it, but also learn the culture of their host societies in order that they can exhibit behaviours appropriate per the culture of those societies. This way, the society itself benefits from the increased diversity and peaceful coexistence of different cultures. Theorists of multiculturalism are in support of cultural diversity and against any systematic discrimination. This theory is so important especially in recent times because, with the rapid growth in telecommunication and transport systems, migrants may want to actively participate in both home and host countries in a radically different way than ever before. This concept is known as transnationalism. This practice will be impossible if the integration policy that is employed by a country is one of assimilation.

While the approach of multiculturalism enjoys so much support, there are others who are against it.However, much of the animosity towards multiculturalism involves immigrant-driven diversity particularly with respect to Muslim immigrants. This assumption is based on the fact that there is no similar retreat from the commitment to multicultural citizenship for indigenous peoples or national minorities (Kymlicka, 2012) ${ }^{12}$.

For the most part, the Republic of Turkey adopts the multiculturalism approach in integrating migrants. For this reason, immigrants in Turkey including Ghanaians and Algerians are able to live peacefully and harmoniously with members of their societies by simply learning the new nuances that pertains in their new locality, and they do not have to unlearn their own cultures.

\subsection{Review of literature on related studies}

The internet is replete with dossier of information pertaining to integration, including ones relating to the subject matter of integration of students. However, there is scanty information with regards to comparison between international students from different countrieswith regards to

\footnotetext{
${ }^{11}$ Duncan, Ivison. The Ashgate Research Companion to Multiculturalism. Ashgate

${ }^{12}$ Kymlicka, W. (2012). Multiculturalism: Success, failure, and the future. Washington, DC: Migration Policy Institute.
}

their integration. Albeit, some work has been done to compare the integration of migrants from different countries of origin, but not necessarily students. For example, in a comparative studies of the integration of migrants from India and China in America which emphasized English language proficiency, it was reported that whereas in 2010 , approximately 63 percent of Chinese immigrants reported having limited English proficiency (LEP). In comparison, only 28 percent of Indian immigrants reported such limitation (LEP).

In a similar comparative study of Indians and the rest of the migrants in US by Kate et al (2011), 72 percent of Indian immigrants in the United States reported either only speaking English or speaking English "very well", but 49 percent of all immigrantsreported either only speaking

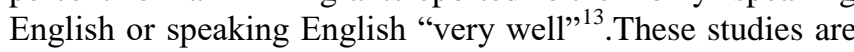
important because limited ability in the language of the host country can have serious consequences on immigrants' integration outcomes. These findings reveal that people from different countries exposed to the same integration policies have different success rates in integration.

Again, in a related study that examined the integration of international students in a Canadian university, the St. Francis Xavier University, Cameron (2006) stated thatinternational students were facing hurdles in the areas of language, food, finances, discrimination, and loneliness, but they have not themselves formed any kind of homogeneous $\operatorname{group}^{14}$.

\section{Research Methodology}

The aim of this study was to discover whether there is a difference in the ability of Algerians and Ghanaians to integrate into the Turkish community. The researcher's assumption was that, with Algerians speaking both Arabic and French, languages from which many Turkish words have their roots, Algerians will be better integrated into the Turkish community than their Ghanaian counterparts if language acquisition and degree of socialization were considered.

The researcher employed qualitative methods to carry out the study because of its flexible nature. Specifically, the researcher used surveys involving questionnaires and interviews, as well as focused group discussions to accomplish this study. The direct nature of the questions on the questionnaire made it easy to analyse, and the interview helped in providing timely responses. Through the focused group discussions, an in-depth understanding of the subject matter was obtained. The researcher settled on these methods because, not only because they complemented each other, but also because they allowed for deeper

\footnotetext{
${ }^{13}$ Kate Hooper, with Susanna Groves, A Comparative Analysis of the Migration and Integration of Indian and Chinese Immigrants in the United States, INTERACT RR 2014/32, Robert Schuman Centre for Advanced Studies, San Domenico di Fiesole (FI): European University Institute, 2014.

${ }^{14}$ International Student Integration into the Canadian University: A Post-World War Two Historical Case Study | History of Intellectual Culture (ucalgary.ca)
} 
understanding of the subject matter, especially with the use of interviews and focused group discussions where followup questions were asked to obtain clarification on anything that seems confusing. Sociological theoretical perspectives and content analysis were used to analyse the findings obtained.

\subsection{Research design}

A research design serves as a framework for measurement and analysis of data. Thus, it functions to show how various parts of the research work together to address the research questions. For the purpose of this study, primary data was used.

The study employed a focused group discussion for each of the groups, and this was held separately. The aim here was to ascertain at firsthand, some of the challenges these groups face during the process of integration.

Also, although the process of integration is multi-faceted, for the purpose of this study, only two dimensions were measured, viz: language acquisition and degree of socialization. To achieve this, Firstly the researcher interviewedsome selected Turkish language teachers who have taught international students from these two countries to solicit their views regarding which of the two categories of international students acquire the language faster. The expectation was that responses will be based on the experiences of the teachers as well as the results from Turkish exams scores for these groups of students. Subsequently, selected participants from the two countries were given questionnaires that test their level of comprehension of the Turkish language.

Also, on the aspect of socialization, a questionnaire was administered to the participants to measure the degree oftheir socialization. A questionnaire refers to a set of carefully designed questions given in exactly the same form to a group of people in order to collect data about some topic(s) in which the researcher is interested ${ }^{15}$.

\subsection{The population and sample}

A research population is generally a large collection of individuals or objects that is the main focus of a scientific query $^{16}$. The target population for this study was the Algerian and Ghanaian international students studying in any of the universities in Ankara. Algeria is in northern Africa. It borders Tunisia and Libya to the east, Niger, Mali, Mauritania to the south, Morocco and Western Sahara to the west, and the Mediterranean Sea to the north. In terms of land mass, it is the second largest country in Africa after Sudan. The country has a population of about 44,643,129people as at July 4, 2021 ${ }^{17}$, and it is ethnically homogenous to some extent, with about 80 percent Arab and 20 percent Berber. Up to 97 percent of the population are

\footnotetext{
${ }^{15}$ Questionnaire - SAGE Research Methods (sagepub.com)

${ }^{16}$ (1) (DOC) Research Population | Mohamed Adam, Hassan Academia.edu

${ }^{17}$ Algeria Population (2021) - Worldometer (worldometers.info)
}

Muslims, and the country and was under the French colony until July 5, 1962.

Ghana on the other hand is located on the west coast of Africa, it is bordered by Cote d'Ivoire in the west, Burkina Faso north, Togo in the east and the Atlantic Ocean in the south. It was a British colony, and it is reputed to be the First Sub-SaharaAfrican country to attain independence from the Europeans ${ }^{18}$.Ghana's population is approximated to be about31,750,883 as at July $4,2021^{19}$. Of this number, about $71.2 \%$ are Christians and only about $17.6 \%$ are Muslims.Adherents of African Traditional religion constitute $5.2 \%$ of the population, other religions are $0.8 \%$ and $5.2 \%$ are pagan. Although the official language in Ghana is English, there are over 60 indigenous languages spoken in the country ${ }^{20}$. Of these languages, Akan is the most widely spoken in the country. Others include GaAdangme, Ewe, Dagbani, Frafra, among others. Obviously, although the two countries are on the continent of Africa, a lot of things set them apart, hence establishing a fertile ground for comparison.

A snow-ballsampling method was used to identify andselect participants from these two countries studying in Ankara while Turkish language teachers were also conveniently sampled to solicit their views with regards to the subject.A sample is simply a subset of the population. The concept of sample arises from the inability of theresearchers to test all the individuals in a given population ${ }^{21}$. In all, 20 Turkish language teachersand35students from each of the two categories of international students (Algerians and Ghanaians) sampled.

\subsection{Procedure for data collection}

After obtaining the consent of the prospective participants, questionnaires assessing their Turkish language comprehension and degree of socialization were administered to them. For purposes of eliminating any difficulty, the researcher took time to explain certain portions of the questionnaire which respondents may not be clear with. Also, to ensure that the participants feel at home and respond to the questions with all sincerity, the researcher assured each participant that their views will be used solely for academic purposes. Subsequently, the researcher discussed with respondents to fix a date and time for focus group discussions. Separate focus group discussions were held for the two differing groups. This allowed for an in-depth understanding of the problems faced by these groups in the process of integrating into the Turkish community. The separate focus group discussions also helped the researcher toclearly see the difference in pattern thought processes of the two group of students regarding the issues raised during the discussion.

\footnotetext{
${ }^{18}$ How African countries left their colonizers | The Japan Times

${ }^{19}$ Ghana Population (2021) - Worldometer (worldometers.info)

${ }^{20}$ Guerini, Federica. 2008. Multilingualism and language attitudes in Ghana: a preliminary survey. ETHNOREMA IV. 4: 1- 33

${ }^{21}$ (1) (DOC) Research Population | Mohamed Adam, Hassan Academia.edu
} 
For the Turkish language teachers, the researcherenquired about teachers who are having both Algerian and Ghanaian students in their class during the time of visit to their schools, or those who taught both international students the preceding year. This was to ensure that the information about these students will not be distorted as a result of the passage of time.

In terms of analysis of the data gathered, on the socialization aspect, the researcher usedcontent analysis to explain the extent to which each group of the target population socializes with the natives of Turkey.With the interviews and focus group discussions data, codes were assigned to them to describe the contents obtained. Patterns were then derived from these codes and names were assigned to them. Finally, a report was generated from the assigned names and presented in a narrative style.

\section{Results and Discussion}

The study sought to establish whether there is any difference in the ability of international students from Algeria and Ghana to integrate into the Turkish community. Integration has a very broad scope, but for the purposes of this study, the researcher narrowed his focus to only two dimensions of integration, namely language acquisition and degree of socialization.

\subsection{Findings from the study}

From the researcher's interaction with the Turkish language teachers which took the form of an interview, focussing largely on the comparative analysis of the Turkish language acquisition abilities of Algerian and Ghanaian students, out of the twenty Turkish language teachers interviewed, sixteen of them representing $80 \%$ confirmed that generally, the Algerian students they have taught over the years acquired the language faster than their Ghanaian counterparts. The remaining $20 \%$ interviewees did not suggest otherwise. Rather, they were indifferent, unable to tell which of the two categories of international students were able to acquire the Turkish language faster between the two groups of students. Probing further to ascertain whether those teachers who thought there were difference know the cause of this discrepancy they reported to have observed over the years, all sixteen respondents gave more or less the same answer, although the interviews were held separately and independently. They all alluded to the fact that because the Turkish language has so many "borrowed" words from the Arabic language, itgives the Arabic language speakers (Algerians) an upper hand over their Ghanaian counterparts. They cited examples of Turkish words like cevap, cemaat, belediye, adam, acaba, muşteri, miras, lugat, kiyamet, kelime, idare, hukuk, heyecan, gurur, fincan, fil, şeriat, şikayet, şükür, şuphe, zeytin, zafer, vekil, Ramazan and a plethora of other words to have originated from Arabic. In addition, words like adaptasyon, ablatif, aktör, ambulans, ananas, anket, avukat, ekran, entegrasyon, gramer, marmelat, otogar, reklam and several others were also said to have their roots from French. Since many Algerians speak both Arabic and French, it makes it easier for them to learn the Turkish language. However, the teachers also revealed that because Turkish is written in Latin rather and not
Arabic alphabets, the Algerians have more difficulty in writing compared to the Ghanaians who speak English and are familiar with the Latin alphabets. Nonetheless, they maintained that overall, the Algerians do better. This assertion was confirmed by the test scores of the questionnaires administered to them which measured their comprehension of the Turkish language, with Algerians scoring higher marks than the Ghanaians overall.

Worthy of mention is the fact that some Turkish words like basketbol, dijital, gol, koç, taksi,çip among others also originated from English language which is the official language of Ghana. But Algerians still have an upper hand over their Ghanaian counterparts the "borrowed words from English are not as many as those from Arabic and French.With this advantage, in the course of learning, Algerians are able to tell accurately the meaning of some words they are seeing or hearing for the first time in Turkish sentences, whereas their Ghanaian counterparts have no clue whatsoever regarding what the word may mean.

On the second dimension of integration considered for the purposes of this study, socialization, one would have thought that those who are able to learn the Turkish language easily (Algerians) will be able to socialize more than those with more limitations regarding language (Ghanaians). On the contrary however, based on the findings in this research, the Ghanaian international students socialize with the Turkish students more than their Algerian counterparts.With this discovery, through the focus group discussions held, the researcher further engaged the international students from the two countries under consideration for purposes of establishing what may be accounting for this development. The following were established during the discussions:

To start with, Ghanaians and Algerians are different in their appearances, with the former being black Africans and the latter predominantly Arabs. This makes Ghanaian international students very conspicuous in their dormitories. According to the Ghanaian respondents, the Turkish students often approach them first to initiate conversations, mostly with the view to learn English language from them. Since they also want to improve their Turkish language, they are often receptive and they easily establish friendship. Subsequently, the Ghanaian students get invited for weekend outings, football matches and other social activities. But most of the Algerian international students do not speak English and not so many Turkish people are interested in learning Arabic or even French.

\section{Limitation, Recommendation and Conclusion}

\subsection{Limitation of the study}

Despite the stringent procedures adopted by the researcher to safeguard thevalidity of this study, it was not free from some hitches. The main limitation of the study is that, although the number of international students were made equal to allow for fair comparison, the equality of the two groups was not in all aspect. This is because, not all the participants in each of these two groups arrived in Turkey on the same day or even around the same time. At the time of 
this study, while there were 9 of the Ghanaian participating students who were in 'Tömer' (Turkish language learning program) and the remaining 26of them in the first year of their study after completing their Turkish language courses, 30 of the Algerian students were in their first year of study and only 5 of them were in 'Tömer'. Those in first year of their studies must have finish learning the Turkish language while those in 'Tömer' are still learning. Again, whereas there were 8 females among the Algerian international students who partook in this study, only 3 female participant was among the Ghanaian respondents.

\subsection{Recommendations}

Undoubtedly, the issue of integration is of immense importance in the subject matter of migration. Especially for international students, a smooth integration process (particularly the dimensions considered in this study) can have a positive impact on their academic performance. Conversely, a problematic integration can spell doom for the students. In a study by Hsiao-ping et al (2015) on the International Students' Challenge and Adjustment to College, specific academic challenges they identified international students to be confronting included communication with professors, classmates, and staff. Consequently, the international studentshave to deal with social isolation when engaging in different group activities. Culturally too, they have difficulty confronting the different ways of thinking and doing things ${ }^{22}$. In the same study also, it was discovered that social adjustment was negatively related to study-performance. Indeed, even in Turkey, there are reports of instances where students abandoned their programs and returned to their home countries due to their inability to learn the Turkish language. Also, many who have stayed but are not proficient in the language end up studying for unduly longer period before they are able to complete their programs.

To help address the problems in language acquisition and socialization, the researcher recommends that prospective international students who have plans of studying in Turkey should learn as many Turkish words, sentences or phrases as possible whilst in their home countries. They can do this by attending a Turkish language class if there is any in their country (Like Yunus Emre Institute) or download telephone or computer applications from which they will be learning. They can as well watch Turkish series and films or listen to Turkish music to familiarize themselves with some Turkish words prior to their travel. This willhave a positive impactwhen they begin learning the Turkish language during“Tömer”).

Finally, I also recommend that infuture studies on this topic, researchers should endeavour to ensure proportionate representation of different genders (males and females)and make samples as similar as possible, especially with regards to the length of stay in Turkey.

\footnotetext{
${ }^{22}$ Hsiao-ping Wu, Esther Garza, Norma Guzman, "International Student's Challenge and Adjustment to College", Education Research International, vol. 2015, Article ID 202753, 9 pages, 2015. https://doi.org/10.1155/2015/202753
}

\subsection{Conclusion}

The findings in this study indicate that based on the backgrounds of individuals, their ability to adapt to new environment and acquire new language may differ. It also confirms the position that the more similar a language is to one's own language, the easier it is for the person to learn. This confirms the position that learners' interlanguage is affected by their native language (L1) during second language (L2) acquisition, and this cross linguistic influence depends on the structural relationship between the two languages. L1 influence occurs primarily due to transfer of structures from the L1 to the L2. Transfer which facilitates acquisition is referred to as positive, and has been found to occur primarily in cases where structure is identical or similar for both languages. Conversely, transferwhich hinders acquisition is referred to as negative, and has been found to occur primarily in cases where the languages are dissimilar (Benson, 2002; Ellis,2008; Jarvis, 2015; Odlin, 1989, 2003; Ringbom, 1992; Tolentino \&Tokowicz, 2011 cited in Shatz, 2017) ${ }^{23}$.

It was also evident in this study that individuals may be weak in some aspects of integration but also be strong in other aspect of it. It is therefore important that people identify their strength and leverage on that to improve their general performance in their efforts to integrate into new communities

\section{References}

[1] Arıkan, R. (2004). Araştırma Tekniklerive Rapor Hazırlama, Asil YayınDağıtım, Ankara.

[2] Asmar, C. (2005). Internationalising students: Reassessing diasporic and local student difference. Studies in Higher Education, 30(3), 291-309.

[3] Balcı, A. (2005). SosyalBilimlerdeAraştırmaYöntem, Teknik veİlkeler. Ankara: Pegem A Yayıncılık.

[4] Barabantseva, E. (2005). Trans-nationalising Chineseness: Overseas Chinese Policies of the PRC's Central Government, Asien, 96:7-28.

[5] Barrie, S. C. (2007). A conceptual framework for the teaching and learning of generic graduate attributes. Studies in Higher Education, 32(4), 439458.

[6] Benson, C. (2002). Transfer / Cross-linguistic influence. ELT Journal, 56, 68-70.

[7] Cameron, J. D. (2006). International student integration into the Canadian university: A post-World War Two historical case study. History of Intellectual Culture, 6(1). Retrieved from http://www.ucalgary.ca/hic/issues/vol6/1

[8] Ellis, R. (2008). The study of second language acquisition (2nd ed.). Oxford, United Kingdom: Oxford University Press.

\footnotetext{
${ }^{23}$ Shatz, I. (2017). Native language influence during second language acquisition: A large-scale learner corpus analysis. Proceedings of the Pacific Second Language Research Forum (PacSLRF 2016), (2015), 175-188. https://doi.org/10.1016/S14733099(10)70030- X
} 
[9] Hallett, R. E. (2010). Homeless: How residential instability complicates students' lives. About Campus, 15(3), 11-16.

[10] İslam, Y. (2005). Araştırma-Yazmave Sunu Teknikleri YönlendirilmişÇalışma I-II SeçkinYayıncılık, Ankara

[11] Jarvis, S. (2015). The scope of transfer research. In L. Yu \& T. Odlin (Eds.), New Perspectives on Transfer in Second Language Learning. Bristol, UK: Multilingual Matters.

[12] Odlin, T. (1989). Language transfer: Cross-linguistic influence in language learning. Cambridge, United Kingdom: Cambridge University Press.

[13] Jochems, W., Snippe, J., Smid, H. J., \& Verweij, A. (1996). The academic progress of foreign students: Study achievement and study behaviour. Higher Education, 31(3), 325-340.

[14] Karasar, N. (2005). BilimselAraştırmaYöntemi. Ankara: Nobel YayınDağıtım

[15] Morrison, J., Merrick, B., Higgs, S., \& Le Métais, J. (2005). Researching the performance of international students in the UK. Studies in Higher Education, 30(3), 327-337.

[16] OECD. (2009). Education at a glance 2009. from http://www.oecd.org/dataoecd/41/25/43636332.p df.

[17] Ringbom, H. (1992). On L1 Transfer in L2 Comprehension and L2 Production. Language Learning, 42, 85-112.

[18] Russell, J., Rosenthal, D., \& Thomson, G. (2010). The international student experience: Three styles of adaptation. Higher Education, 60(2), 235-249.

[19] Tinto, V. (1975). Dropout from higher education: A theoretical synthesis of recent research. Review of Educational Research, 45(1), 89-125.

[20] Tolentino, L. C., \&Tokowicz, N. (2011). Across Languages, Space, and Time. Studies in Second Language Acquisition, 33, 91-125.

[21] Whatley, M. \&Batalova, J. (2013). Limited English Proficient Population of the United States [online]. Migration Information Source, 25 July, available on: http://www.migrationpolicy.org/article/limitedenglish-proficient-population-united-states 